\title{
Frozen elephant trunk: an option for everyone?
}

\author{
Amer Harky, Ahmed Othman, Mark Field \\ Department of Cardiothoracic Surgery, Liverpool Heart and Chest Hospital, Liverpool L1, UK.
}

Correspondence to: Prof. Mark Field, Department of Cardiothoracic Surgery, Liverpool Heart and Chest Hospital, Thomas drive L14 3PE, Liverpool L1, UK. E-mail: mark.field@lhch.nhs.uk

How to cite this article: Harky A, Othman A, Field M. Frozen elephant trunk: an option for everyone? Vessel Plus 2021;5:25.

https://dx.doi.org/10.20517/2574-1209.2021.26

Received: 10 Feb 2021 Accepted: 12 Apr 2021 Published: 14 May 2021

Academic Editor: Cristiano Spadaccio Copy Editor: Xi-Jun Chen Production Editor: Xi-Jun Chen

Keywords: Aorta, frozen elephant trunk, patient, outcome

Dear Editor,

We read with interest the recent article by Di Marco et al. ${ }^{[1]}$ in which they have outlined their experience with using frozen elephant trunk (FET) in different pathologies of the thoracic aorta. They briefly described their practice since 2007 in over 318 procedures using the two commonly available conduit types: $n=173$ using E-Vita Open and E-Vita Open Plus (Jotec GmbH, Hechingen, Germany) and $n=145$ using Thoraflex (Vascutek, Terumo, Inchinnan, Scotland, UK). The majority of their patients that needed FET were those with residual dissection in operated acute type A aortic dissection $(37 \%, n=119)$ followed by those with chronic degenerative aortic aneurysms $(26 \%, n=82)$. A further endovascular extension was performed in 85 patients due to incomplete thrombosis of the false lumen and to less extent, inadequate distal sealing. Their idea and recommendation of a graft length of $100 \mathrm{~mm}$ for acute dissection and 130-160 $\mathrm{mm}$ for chronic aneurysms of thoracic aorta can contribute to minimizing the risk of post-operative neurological complications, in particular spinal cord ischaemia due to shorter length of cover of the descending thoracic aorta.

Since the early days of conventional elephant trunk (CET) surgery in 1983 and subsequently the development of FET during 2003, outcomes have been gradually improving including mortality and the fate of the false lumen ${ }^{[2,3]}$. Yet, the evidence evolves in utilizing FET and in particular the risk of paraplegia and false lumen thrombosis with further research coming into light. Di Marco et al. ${ }^{[1]}$ had a $26.6 \%(n=85)$ rate 
of requirement for further re-intervention following the deployment of FET, which is significantly high and these question the safety of recommending a $100 \mathrm{~mm}$ vs. 130-160 mm graft length in their "idea" of using the FET graft.

We all know that using the FET device offers many solutions to acute and chronic pathologies of thoracic aorta and it has undoubtedly saved many lives. However, the FET is not a benign addition to the conventional elephant trunk; we believe caution should be taken in patients with borderline indication, where the sole purpose is an endovascular platform for distal diseases that are not requiring treatment immediately. Using FET in patients who are not "ideal" candidates can result in incremental and, perhaps, unnecessary risks of paraplegia, quadriplegia, distal stent-graft induced entry tear, endoluminal thrombosis, endoleaks and pressurization from false lumen ${ }^{[4]}$. Also, the risks associated with chronic dissection flaps such as sizing issues and stent coarctation should not be ignored. In our opinion, careful patient selection with favorable anatomy and available multidisciplinary expertise is an ideal approach to minimizing the risk of avoidable complications at the initial procedure.

\section{DECLARATIONS}

\section{Authors' contributions}

Reviewed and approved final form of the letter to editor: Harky A, Othman A, Field M

All authors contributed equally to this paper.

Availability of data and materials

Not applicable.

\section{Financial support and sponsorship}

None.

\section{Conflicts of interest}

All authors declared that there are no conflicts of interest.

\section{Ethical approval and consent to participate}

Not applicable.

\section{Consent for publication}

Not applicable.

\section{Copyright}

(c) The Author(s) 2021.

\section{REFERENCES}

1. Di Marco L, Votano D, Leone A, Pacini D. Frozen elephant trunk: assets and liabilities of a challenging technique. Vessel Plus 2020;4:32. DOI

2. Borst HG, Walterbusch G, Schaps D. Extensive aortic replacement using "elephant trunk" prosthesis. Thorac Cardiovasc Surg 1983;31:37-40. DOI PubMed

3. Karck M, Chavan A, Hagl C, Friedrich H, Galanski M, Haverich A. The frozen elephant trunk technique: a new treatment for thoracic aortic aneurysms. J Thorac Cardiovasc Surg 2003;125:1550-3. DOI PubMed

4. Harky A, Fisher RK, Field ML. Management of a compromised frozen elephant trunk due to acute type b aortic dissection. Vasc Endovascular Surg 2020;54:756-9. DOI PubMed 